\title{
Race-related variation of facial features: Anthropometric data I
}

\author{
ALVIN G. GOLDSTEIN \\ University of Missouri, Columbia, Missouri 65211
}

\begin{abstract}
Physical anthropological measures of faces of Japanese, whites, and blacks were obtained from several published sources. Comparisons among three racial groups yielded no evidence for racial differences in facial heterogeneity, but features of Japanese women's faces may display more variation than the other faces studied.
\end{abstract}

Recent laboratory research has shown that white American subjects remember white faces better than they remember black or Japanese faces (Chance, Goldstein, \& McBride, 1975; Cross, Cross, \& Daly, 1971; Malpass \& Kravitz, 1969). Additional evidence suggests that black subjects remember black faces better than they remember white or Japanese faces (Chance et al., 1975; Shepherd, Deregowski, \& Ellis, 1974). Anecdotal evidence seems to support the notion that, in general, "other-race" faces are perceived to be more alike (i.e., more homogeneous) and therefore are less discriminable than "own-race" faces. Explanations of this performance deficit, hereinafter called the other-race effect, fall into two broadly defined categories, psychosocial or psychophysical. Psychosocial explanations attribute the poor performance observed in identifying other-race faces to the effects of prejudice, or unfamiliarity with the class of stimuli, or a variety of other interpersonal factors. Psychophysical explanations emphasize stimulus attributes such as loss of facial details with decreased reflectance from dark skin, or race-related differences in variability of facial features. The implications of the latter explanation have been explored in this research. In particular, we have attempted to obtain evidence to confirm this hypothesis: If the features of Japanese faces are more homogeneous than the features of white faces, then perceptual discrimination among Japanese faces compared to white faces should be impaired. Essentially this hypothesis asserts that within-race variability of size and shape of facial features is lower among Japanese (or black) faces than among white faces, and this lack of heterogeneity causes viewers to confuse Japanese faces more than they confuse white faces.

In their attempts to study the other-race effect, investigators have, with some justification (see below), neglected to further analyze the face stimuli used in their research. Instead, white, black, and Japanese faces have simply been used as stimuli, suggesting that the investigators have assumed the independent variable in their experiments to be the visible signs of racial membership, the "orientalness," the "blackishness," and the "whitishness" of the face.

Since the differences among the groups of faces representing the various races are the independent variables in these experiments, it is reasonable to question the extent to which the independent variables were under the experimenters' control. For instance, if the variable "orientalness" was always confounded with a reduced degree of feature variability, then the other-race effect would have less to do with the "race" of the face and more to do with the well known principles governing discrimination of and memory for visual patterns and configurations. Stated in other terms, if race and diversity of facial features are confounded, then other-race recognition errors could be attributed to either the "race" variable (i.e., orientalness) or to the greater confusability of the Japanese faces. If it could be demonstrated that Japanese faces as a group are physically more alike than white faces, it would be reasonable to attribute errors of recognition to a simple psychophysical function and not to an interesting social psychological phenomenon.

On the one hand, some evidence suggests that it might not be fruitful to analyze the independent variable in search of a hidden confounding variable, as the otherrace effect is probably reciprocal. Thus, blacks have difficulty recognizing white faces and whites have difficulty recognizing black faces (Chance et al., 1975; Shepherd et al., 1974). It follows from these findings that the explanation of the other-race effect is not to be found in differences between stimulus configurations, but most likely will be discovered in factors peculiar to the observer. Furthermore, anthropologists often find that "in-groups" think (and say) that "out-groups" all look alike (Robbins, Note 1). Although this subjective estimate of within-group similarity may have little basis in fact (Goldstein \& Chance, 1976, 1978, 1979), its ubiquity does suggest the other-race effect is reciprocal. On the other hand, not all the evidence supports the reciprocity notion (Cross et al., 1971; Malpass \& Kravitz, 1969), and differential experience with other-race faces adds confusion to an already complicated situation. So, even though the weight of the evidence, weak as it is, favors a psychosocial rather than a psychophysical explanation of the other-race effect, enough residual doubt remains to warrant a study of the facial topography of various racial groups to explore the extent of within-group feature variability. This decision was facilitated by the knowledge that anthropological data on faces of living people were available from the physical anthropology literature.

\section{PROCEDURES FOR COLLECTING ANTHROPOMETRIC DATA}

The original data consisted of standard craniofacial measurements on men and women of white, Japanese, and black 
ancestry. All entries in Table 1 were obtained from sources cited in the footnote to the table. Entries in the body of Table 1 are coefficients of variation (CVs) derived from the original tabulated means and standard deviations. A CV is a percent score, calculated by dividing the standard deviation of a set of measures by its mean and multiplying the quotient by 100 ; it is commonly used by physical anthropologists to compare variability of one sample with another sample when their means differ. Thus the larger the value, the greater the variation of the individual measures making up the mean. One criterion was used to select the measures included in Table 1: Each measure had to have data obtained from at least two different racial groups. Thirty-nine measures were found that fit this criterion. Headsize measures were included because they are assumed to play a role in face recognition, although evidence for this assumption is primarily intuitive. Anthropologists have standardized most if not all of the measures they use to describe the human head and body, but, unfortunately, not all relevant measurements are collected by all anthropologists, a condition that explains why there are missing entries in Table 1 . Craniofacial measurements on white Americans could not be located. Instead, Caucasian faces are represented by measurements of individuals with northern European, Russian, and Irish ancestry.

Some help with the terminology of Table 1 is called for; for more details about the meaning of the various measures, consult the references cited in Table 1 . In general, features (nose, face height, etc.) are measured linearly in millimeters, while indexes are derived from combinations of these primary measures. Thus, for example, dividing the breadth of the nose by its height and multiplying by 100 gives the nasal index. Indexes are, therefore, always more complex measures than primary data. Bizygomatic and bigonial widths refer to the maximum width of the face measured approximately at the level of the opening to the ear canal and at the level of the mandible, respectively. Facial index refers to the relative narrowness of the face; zygofrontal and zygogonial indexes refer, respectively, to the breadth of the forehead in relation to the width of the face and to the breadth of the lower jaw (at just below the ear lobes) in relation to the width of the face. Interocular and biocular widths are the distances between the two inner corners and between the two outer corners of both eyes, respectively. Malar refers to the cheek area. Asterisks call attention to measures taken by

Table 1

Coefficients of Variation of Craniofacial Features of White, Japanese, and Black Men, and of Women from Northern Europe, Japan, Russia, Ireland, Bougainville, and the United States

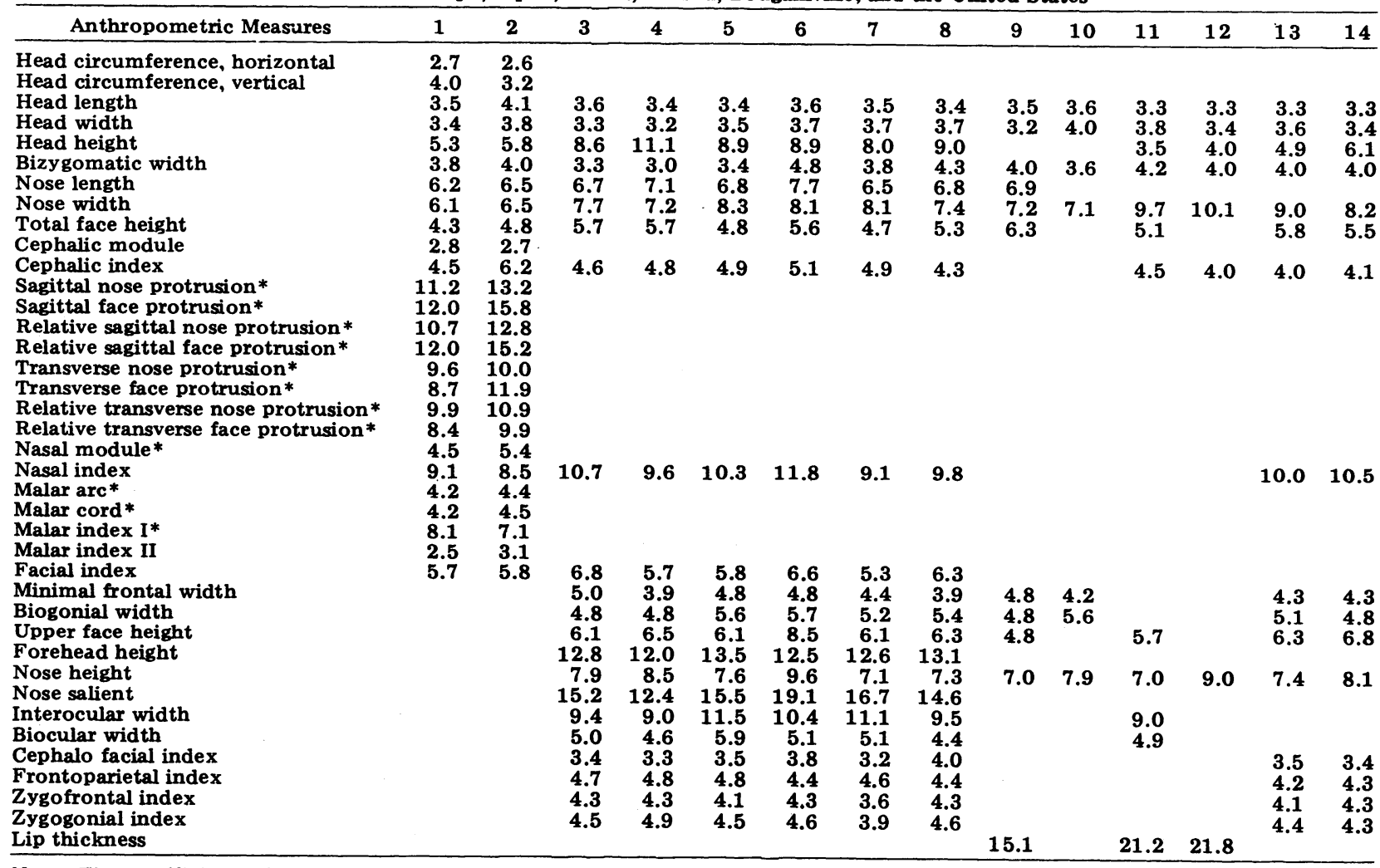

Note-The coefficient of variation (SD/mean $\times 100)$ is a common statistic used by anthropologists to compare the variability of one measure with another when the measures differ in mean value. All anthropometric measures were taken on living individuals. For explanations of measures without asterisks (*), see elementary physical anthropology text (e.g., Montague, 1960; Olivier, 1969). For measures with asterisks, see Steegmann (1972); for instrument developed to take these measures, see Steegmann (1970). Data for Columns 1 and 2 were adapted from Steegmann (1972). Subjects were college age men; both groups were born in Hawaii, but one group was composed of Caucasians of northern European ancestry (Column $1, N=25$ ) and the other was composed of Japanese of unmixed Japanese ancestry (Column 2, $N=33$ ). Ancestry information was obtained from the abjects. Columns 3-8 were adapted from Shapiro (1939). All six groups of men and women were of "unmixed Japanese ancestry" (p. 7). One group of men (Column 3, $N=172$ ) and women (Column $4, N=91$ ) were born in Japan and lived there at the time the measures were taken; a second group (Column 5-men, $N=176$; Column $6-$ women, $N=93$ ) were migrants to Hawaii and were "blood relatives" (p. 9) of the first group; the last group (Column $7-m e n, N=187$; Column $8-w o m e n, N=90$ ) were the children of the immigrants and all were born in Hawaii. Age ranges of the groups were 20-64 years, 20-64 years, and $20-49$ years, respectively. Data for Column 9 (R ussian men, $N=55$ ) were adapted from Miklasheuskaya (1966). All subjects were Caucasians, 7 , attending Moscow schools. Data for Column $10(N=526)$ were adapted from Friedlaender (1975). Subjects were black men 21.70 years of age, from 18 villages on Bougainville Island, one of the Solomon Islands. Data for Columns 11 (men, $N>500$ ) and 12 (women, $N>500$ ) were adapted from Herskovits (1930). The original subject population included 962 men and 931 women, all over the age of 21 years, most of whom were born in the U.S. Of this group, about $13 \%$ originated in the Islands of the Caribbean. Not all of the subjects in the population were measured on all features; $N$ varies but is never less than 500 . Data for Columns 13 and 14 were adapted from Hooton and Dupertuis (1955). Subjects were Irish men (Column 13, N=10,553), 15-94 years of age from about 19 counties in Ireland, and Irish women (Column 14, N=1,801) 15-69 years of age from 7 counties in Ireland. 
Steegmann (1972) with a specially developed contourometer (Steegmann, 1970), a device that measures the fairly complex geometric relationships formed when nose, chin, and cheek surfaces interset.

\section{EXAMINATION OF CRANIOFACIAL COEFFICIENTS OF VARIANCE}

The primary reason for collecting and studying the anthropological data tabulated in Table 1 is to answer the question "Do white, Japanese, and black faces differ in feature variability?" Accordingly, an answer to this question will be considered in the remaining sections of this article. Descriptions of additional findings in connection with feature variability as it is related to gender, age, and salience in facial identification will be presented in a subsequent report (Goldstein, 1979).

\section{Racial Differences in Feature Variability}

To discover whether feature variability differs within racial groups, CV values of the three races must be compared on each of the measures. For this comparison, CV values of Table 1 could be used in their present form, but it is evident that this procedure would be cumbersome, and, in the final analysis, might result in a biased conclusion because the sizes of several samples in Table 1 are quite small. Accordingly, these considerations were taken into account, and new mean CV values for men and women separately were computed from the combined CV values of the white, Japanese, and black samples. For example, by combining the data of Columns $2,3,5$, and 7 , mean values were calculated for Japanese men. Table 2 presents these averaged mean coefficients for 23 of the 38 measures of Table 1. The missing measurement categories were omitted because data were not available on at least two racial groups (within sex).

Japanese vs. white faces. Comparison of Japanese with both groups of white faces (European plus Russian, and Irish; see note, Table 2) provides a measure of the relative variability of the features of the members of both races. Thus in Table 2 Japanese men's coefficients exceeded the European-Russian combined means in 9 of the 14 comparisons, with both groups equal on 2 measures. Japanese also exceeded the Irish mean CV on 7 of the 16 measures. So, Japanese men's faces are no more or less variable than either group of white faces. Japanese women's CV values are found to be larger than white women's scores in 10 of 16 comparisons and equal on 3 comparisons. Again, there is no evidence in these data for any race-related difference in facial variability. Across-sex comparisons yield somewhat more interesting results. Japanese women's measures are larger than the European-Russian male values in 11 of 14 comparisons (and equal on 1), and also in 11 of 16 comparisons (1 equal) with the Irish sample of white men. Thus, in 22 out of a possible 30 comparisons (73\%), Japanese women's faces are more heterogeneous than white men's faces. This slight advantage for the Japanese is balanced by the finding that Japanese men's faces and white women's faces do not differ in variability (Japanese men's coefficients are larger on seven comparisons, smaller on seven, and equal on two).

A somewhat more comprehensive source of information about Japanese-white feature complexity is available by comparing the Hawaiian-born white and the Hawaiian-born Japanese samples (Columns 1 and 2) shown in Table 1. On 21 of Steegmann's (1972) 26 measures (about 80\%), Japanese men's facial features are more complex than white men's features. Unfortunately, only 25 white and 33 Japanese men were measured in Steegmann's study, so conclusions involving these data should be drawn with caution.

Taken together, these data clearly indicate that there is no support for the contention that Japanese faces are

Table 2

Averages of Mean Coefficients of Variation for Japanese, White, and Black Men and Women (Data Combined from Table 1)

\begin{tabular}{|c|c|c|c|c|c|c|c|}
\hline & \multicolumn{2}{|c|}{ Japanese Faces } & \multicolumn{3}{|c|}{ White Faces } & \multicolumn{2}{|c|}{ Black Faces } \\
\hline & $\begin{array}{c}\text { Men } \\
(2,3,5,7) \\
\end{array}$ & $\begin{array}{l}\text { Women } \\
\cdot \quad(4,6,8) \\
\end{array}$ & $\begin{array}{c}\text { European and } \\
\text { Russian * } \\
(\mathbf{1}, \mathbf{9})\end{array}$ & $\begin{array}{l}\text { Irish* } \\
\text { (13) }\end{array}$ & $\begin{array}{c}\text { Women } \\
\text { (14) }\end{array}$ & $\begin{array}{c}\text { Men } \\
(10,11)\end{array}$ & $\begin{array}{c}\text { Women } \\
\text { (12) }\end{array}$ \\
\hline $\begin{array}{l}\text { Head length } \\
\text { Head width } \\
\text { Head height } \\
\text { Bizygomatic width } \\
\text { Nose length } \\
\text { Nose width } \\
\text { Total face height } \\
\text { Cephalic index } \\
\text { Nasal index } \\
\text { Facial index } \\
\text { Minimum facial width } \\
\text { Bigonial width } \\
\text { Upper face height } \\
\text { Forehead height } \\
\text { Nose height } \\
\text { Nose salient } \\
\text { Interocular width } \\
\text { Biocular width } \\
\text { Cephalo facial index } \\
\text { Frontoparietal index } \\
\text { Zygofrontal index } \\
\text { Zygonial index } \\
\text { Lip thickness }\end{array}$ & \begin{tabular}{|r|}
3.5 \\
3.5 \\
8.3 \\
3.5 \\
6.6 \\
8.0 \\
$\mathbf{5 . 0}$ \\
4.9 \\
$\mathbf{9 . 9}$ \\
$\mathbf{5 . 9}$ \\
4.7 \\
$\mathbf{5 . 2}$ \\
$\mathbf{6 . 1}$ \\
$\mathbf{1 3 . 0}$ \\
$\mathbf{7 . 5}$ \\
$\mathbf{1 5 . 8}$ \\
$\mathbf{1 0 . 7}$ \\
$\mathbf{5 . 3}$ \\
$\mathbf{3 . 4}$ \\
$\mathbf{4 . 7}$ \\
$\mathbf{4 . 0}$ \\
$\mathbf{4 . 3}$
\end{tabular} & \begin{tabular}{r|}
3.5 \\
3.5 \\
9.7 \\
4.0 \\
7.2 \\
7.6 \\
5.5 \\
4.7 \\
10.4 \\
6.2 \\
4.2 \\
$\mathbf{5 . 3}$ \\
$\mathbf{7 . 1}$ \\
12.5 \\
$\mathbf{8 . 5}$ \\
$1 \mathbf{5 . 4}$ \\
$\mathbf{9 . 6}$ \\
$\mathbf{4 . 7}$ \\
$\mathbf{3 . 7}$ \\
$\mathbf{4 . 5}$ \\
$\mathbf{4 . 3}$ \\
$\mathbf{4 . 7}$
\end{tabular} & $\begin{array}{l}\mathbf{3 . 5} \\
\mathbf{3 . 3} \\
\mathbf{5 . 3} \\
\mathbf{3 . 9} \\
\mathbf{6 . 7} \\
\mathbf{6 . 9} \\
\mathbf{5 . 7} \\
\mathbf{4 . 5} \\
\mathbf{9 . 1} \\
\mathbf{5 . 7} \\
\mathbf{4 . 8} \\
\mathbf{4 . 8} \\
\mathbf{4 . 8} \\
\mathbf{7 . 0} \\
\\
\end{array}$ & $\begin{array}{r}3.3 \\
3.6 \\
4.9 \\
4.0 \\
9.0 \\
5.8 \\
4.0 \\
10.0 \\
4.3 \\
5.1 \\
6.3 \\
7.4\end{array}$ & $\begin{array}{r}3.3 \\
3.4 \\
6.1 \\
4.0 \\
8.2 \\
5.5 \\
4.1 \\
10.5 \\
4.3 \\
4.8 \\
6.8 \\
8.1\end{array}$ & $\begin{array}{l}3.4 \\
3.9 \\
3.5 \\
3.9 \\
\\
8.4 \\
5.1 \\
4.5 \\
\\
4.2 \\
5.6 \\
\mathbf{5 . 7} \\
\\
7.4 \\
\mathbf{9 . 0} \\
4.9\end{array}$ & $\begin{array}{r}3.3 \\
3.4 \\
4.0 \\
4.0 \\
10.1 \\
4.0\end{array}$ \\
\hline
\end{tabular}

Note-Numbers in parentheses refer to the columns of Table 1 whose data were combined to produce the new mean values shown here. When combining means differing by more than a few cases in sample size, adjustments were made by weighting means with their associated $N$ values: $\left(N_{1} \bar{X}_{1}+\ldots+N_{n} \bar{X}_{n}\right) /\left(N_{1}+\ldots+N_{n}\right)$. Adjustments were performed only when combining the data of Japanese men, black men, and when combining the Russian sample with the European sample. *The Irish men's data, based on over 10,000 cases, could not be combined with the Russian and European men's data because of the vast discrepancy in sample size. For this reason, two separate white men's samples have been computed. 
more difficult to recognize or remember because they are more alike, or that their features are less variable than the features of white faces. In fact, the evidence seems to favor the conclusion that Japanese faces may be more variable than white faces. Whether Japanese faces are equal to or more variable than white American faces in feature variability is still an open question that can be answered only by additional research. Nevertheless, two facts support a prediction that adding white American measurements will not alter the tentative conclusions reached here. First, the Japanese data have been informally compared to limited sets of other craniofacial measures collected from several samples of white faces; no evidence has been found to suggest that whites are more variable than Japanese. Second, from an examination of facial measurements from many different subgroups within larger populations (e.g., Swedes, Iroquois Indians, Uzbeks, etc.), it is evident that even though the mean dimensions of facial features may differ from one group to the next (so that, for example, mean forehead height may be greater in one group than in another), CVs tend to be relatively stable within each measurement category. In other words, the degree of feature variability in one population is similar to that found in other populations; "race" seems to account for little of the variance in heterogeneity of features, although it may account for differences in mean dimensions.

Black vs. white faces. Comparisons between black and white groups are hindered by the small number of mesurements common to both groups. Notice, also, that only 5 of 13 entries for black men in Table 2 represent the combined mean of two black samples, with the remaining 8 entries derived from one or the other of the two black samples (see Table 1, Columns 10 and 11). Fortunately, each black sample is represented by over 500 cases. With these limitations in mind, little more can be said about the black-white comparisons other than to note that the data yield no evidence for the existence of race-related differences in features variability in the men's measurements. Meaningful interpretation of the black-white comparisons of the women's data is precluded by the small number of blackwhite comparisons, since only seven white facial measurements were balanced by corresponding black entries. In brief, from these limited data, it is concluded that feature variability in black faces is apparently no different than variability in white faces. Therefore, recognition of black faces by white observers is most probably not deficient because of psychophysical factors.

From all the foregoing measurements, collected on a variety of samples, the most prudent conclusion to draw is that the explanation of the other-race effect most probably will not be found in factors associated with differences among the races in the variability of facial features. None of the data collected so far suggests that the confusion among Japanese faces and among black faces experienced by white observers is caused by a lack of physical variation in the features of either Japanese or black faces. In fact, Japanese faces, and especially Japanese women's faces, may display slightly greater feature variability than white faces. One explana- tion for the other-race effect can now be rejected with a fair degree of confidence. Craniofacial measurements on the three racial groups suggest that the difficulty experienced in recognizing other-race faces is probably not a function of psychophysical factors. Evidently, the extent to which dimensions of facial features vary is not systematically related to race. Thus, for example, if we assume that the broader the range of feature dimensions within a population, the more perceptually dissimilar individual members of the group will appear, then the findings reported here suggest that faces in each of the races are, so to speak, arranged at equal intervals along the similarity dimension. These results are compatible with measures of psychological similarity among Japanese and white faces (Goldstein \& Chance, 1979).

\section{REFERENCE NOTE}

1. Robbins, M. Personal communication, October 1978.

\section{REFERENCES}

Chance, J., Goldstein, A. G., \& McBride, L. Differential experience and recognition memory for faces. Journal of Social Psychology, 1975, 97, 243-253.

Cross, J. F., Cross, J., \& DALY, J. Sex, race, age and beauty as factors in recognition of faces. Perception \& Psychophysics. 1971, 10, 393-396.

Friedlaender, J. S. Patterns of human variation. Cambridge: Harvard University Press, 1975.

Goldstein, A. G. Facial feature variation: Anthropometric data II. Bulletin of the Psychonomic Society, 1979, 13, 191-193.

GolDstein, A. G., \& C HANCE, J. Measuring psychological similarity of faces. Bulletin of the Psychonomic Society, 1976, 7, 407-408.

Goldstein, A. G., \& Chance, J. Judging face similarity in own and other races. Journal of Psychology, 1978, 98, 185-193.

Goldstein, A. G., \& Chance, J. Do "foreign" faces really look alike? Bulletin of the Psychonomic Society, 1979, 13, 111-113.

Herskovits, M. J. The anthropometry of the American negro. New York: Columbia University Press, 1930.

Hooton, E. A., \& Duperturs, C. W. The physicial anthropology of Ireland. Papers of the Peabody Museum of Archeology and Ethnology, 1955, 30, Nos. 1 and 2.

MalPass, R. S., \& KRAVITz, J. Recognition for faces of own and other race. Journal of Personality and Social Psychology, 1969, 13, 330-335.

Miklashevskaya, N. M. Growth of the head and face in boys of various ethnic groups in the USSR. Human Biology, 1966, 38, 231-250.

Montagu, M. F. A. A handbook of anthropometry. Springfield, Ill: Thomas, 1960.

Olivier, G. Practical anthropology. Springfield, Ill: Thomas, 1969.

ShapIRO, H. L. Migration and environment. New York: Oxford University Press, 1939.

Shepherd, J. W., Deregowski, J. B., \& Ellis, H. D. A crosscultural study of recognition memory for faces. International Journal of Psychology, 1974, 9, 205-211.

Steegmann, A. T., JR. Reliability testing of a facial contourometer. American Journal of Physical Anthropology, 1970, 33, 241-248.

Steegmann, A. T., JR. Cold response, body form, and craniofacial shape in two racial groups of Hawaii. American Journal of Physical anthropology, 1972, 37, 193-222.

(Received for publication January 15, 1979.) 